\title{
lodine and Selenium as Antiviral Agents: Potential Relevance to SARS-CoV-2 and Covid-19
}

\author{
Margaret P Rayman* \\ Faculty of Health and Medical Sciences, Department of Nutritional Sciences, University of Surrey, UK
}

\begin{abstract}
lodine and selenium are linked through their effects on thyroid function. Both also have anti-viral properties relevant to SARS-CoV-2 infection. In the form of povidone-iodine solution, iodine is a virucidal agent that has been shown in vitro to kill the coronaviruses SARS-CoV and MERS-CoV, implicated in previous coronavirus epidemics. Viral loads of SARSCoV-2 are high in the nasal cavity, nasopharynx, and oropharynx. Under in-vitro conditions mimicking nasopharyngeal secretions, povidone-iodine solution significantly inactivated SARS-CoV-2, hence some health-care workers in intensivecare units, dental treatment or maxillofacial surgery are using topical povidone-iodine solution, at $0.5 \%$. However, those using topical povidone-iodine solution prophylactically over a period of months might experience adverse effects on thyroid function from exposure to excess iodine, particularly if they have insufficient intake of selenium. Selenium has a protective function on the thyroid; on exposure to excess iodine, too much hydrogen peroxide is produced which is removed by a selenoprotein, glutathione peroxidase. In addition to its protective function on the thyroid, selenium is acknowledged, independently, to combat a number of viral diseases. Observational studies have associated higher selenium status with better recovery from COVID-19 and poorer selenium status is associated with COVID-19 death. Invitro evidence shows that SARS-CoV-2 reduces the expression of selenoproteins that protect against viral disease. It is therefore advisable to ensure adequate selenium intake, particularly in countries with low or marginal selenium status. Finally, for those using povidone-iodine prophylactically in such countries, a modest oral supplement of selenium, such as $100 \mu \mathrm{g} / \mathrm{d}$, might be advisable.
\end{abstract}

\section{Keywords}

lodine, Selenium, Povidone-lodine, SARS-Cov-2, COVID-19, Topical treatment

\section{Introduction}

Both iodine and selenium are essential trace elements required in microgram quantities that are known to have antiviral effects. They are both essential for the functioning of the thyroid and its hormones. Since the advent of SARS-CoV-2, a further synergy between these elements in the potential control of COVID-19, the disease caused by this new virus, has become apparent.

\section{Potential Efficacy of Mouthwashes to Reduce SARS-Cov-2 Viral Load and Transmission}

During early COVID-19 disease, the throat and salivary glands were shown to be major sites of viral replication and transmission suggesting that oral antiseptics might be effective anti-viral agents [1]. If so, they would be particularly relevant to oral health-care providers who are at an elevated risk of exposure to COVID-19 due to their proximity to the nasopharynx of patients and the use of aerosol-generating equipment. Thus, Meister and colleagues evaluated the virucidal activity of eight commercially available oral rinses, including recognised antiviral agents such as hydrogen peroxide and clorhexidine, against three different strains of SARS-CoV-2 under in vitro conditions that mimicked nasopharyngeal secretions. In the case of three products, exposure times of 30 seconds were sufficient to inactivate SARS-CoV-2 significantly, supporting the idea that oral rinsing might reduce the viral load in saliva thus potentially reducing transmission [1]. The three effective mouthwashes were Dequonal (active ingredients: equalinium chloride, benzalkonium chloride), Listerine Cool Mint (active ingredients: ethanol, essential oils) and Iso-Betadine mouthwash $1.0 \%$ (active ingredient: povidone-iodine). These reduced viral infectivity by up to three orders of magnitude compared to the background level, i.e. with log reduction factors of $\geq 3.11, \geq 2.78$ and $\geq 2.61$ for the three strains of

*Corresponding author: Margaret P Rayman, Faculty of Health and Medical Sciences, Department of Nutritional Sciences, University of Surrey, UK

Accepted: November 24, 2020

Published online: November 26, 2020

Citation: Rayman MP (2020) lodine and Selenium as Antiviral Agents: Potential Relevance to SARS-CoV-2 and Covid-19. Archives Oral Maxillofac Surg 3(1):69-76 
SARS-CoV-2 [1]

Topical lodine, Povidone-lodine, as an Antiseptic Agent against Coronaviruses Including SARS-CoV-2

Of these three mouthwashes, it has been hypothesised that povidone-iodine (PVP-I) at $0.5 \%$, administered as a nasal spray and mouthwash/gargle [2], will kill SARS-CoV-2 in vivo in the oronasal cavities and hence may reduce cross infection from patients to healthcare workers and vice versa. Clearly, this may be relevant for hospitalised patients with COVID- 19. However, it is potentially just as important in reducing cross-infection from those with asymptomatic COVID infection to healthcare workers who work close to the nose and mouth, i.e. dentists, oral and maxillofacial surgeons, ENT surgeons, ophthalmologists, anaesthetists, and vice versa.

PVP-I is a stable chemical complex of polyvinyl pyrrolidone (povidone, PVP) and iodine that contains the $\mathrm{I}_{3}{ }^{-}$ion and is able to release elemental iodine on contact with tissues; it is extensively used as an antiseptic in surgical procedures $[3,4]$. PVP-I has higher virucidal activity than other commonly used antiseptic agents including chlorhexidine and benzalkonium chloride [2]. PVP-I has been shown to be active in vitro against coronaviruses that caused earlier epidemics, namely SARS-CoV that was implicated in the SARS epidemic of 20022003 and MERS-CoV that caused the MERS epidemic of 20122013 [2,5-7].

Numerous in-vitro studies have concluded that PVP-I solution, even at concentrations as low as $0.5 \%$, has rapid and effective virucidal activity against SARS-CoV-2; for instance the SARS-CoV-2 USA-WA1/2020 strain was completely inactivated within 15 seconds of contact $[1,8,9]$. Frank and colleagues have reviewed the literature on the use of PVP-I and have concluded that it can safely be used in the nose at concentrations up to $1.25 \%$ and in the mouth at concentrations up to $2.5 \%$ for up to 5 months [10]. A number of groups now advocate the use of $0.5 \%$ PVP-I solution in healthcare workers and their patients in addition to the recommended personal protective equipment to minimise the risk of spread of COVID-19, [2,11-13]. At the time of writing, two randomised trials had been registered that were aimed at reducing the viral load in confirmed COVID-19 patients; these plan to use solutions of antiviral agents including PVP-I as nasal sprays and oropharyngeal washes [1].

\section{Are There Risks in Using PVP-I As an Oral Rinse and Nasal Spray?}

Use of $0.5 \%$ PVP-I solution as a nasal spray, mouth-wash and gargle by staff in intensive care units as suggested by Kirk-Bayley and colleagues $[2,12]$ and by Pullen and Croser in dental procedures [13] may run the risk of over-exposure to iodine if used frequently; this could well be the case for healthcare workers who may be tending patients over a period of months or for dental practitioners. The doses of iodine recommended by Kirk-Bayley and colleagues are a maximum iodine intake of $3.52 \mathrm{mg} / \mathrm{d}$ for healthcare workers. For healthcare workers or dental practitioners whose exposure is likely to endure for a longer period, that dose, $3,520 \mu \mathrm{g} / \mathrm{d}$, is more than three times the US Tolerable Upper Limit of intake of $1,100 \mu \mathrm{g} / \mathrm{d}$ [14] and almost six times the European Food Safety Association (EFSA) Upper Limit of $600 \mu \mathrm{g} / \mathrm{d}$ [15]. Of course, not all the dose will be ingested but a proportion will be, suggesting the need for monitoring of thyroid function in healthcare workers or dental personnel exposed to this level of iodine exposure over a period of many weeks or months. Another factor to be considered is that the kidneys are the major route by which excess iodine is excreted [16] suggesting that such iodine treatment may be contraindicated in anyone with poor kidney function.

Despite the concerns expressed above, there are a number of examples of human exposure to iodine solution by mouth over an extended period that gave no evidence of toxicity [17-19]. For instance, once-daily use of a PVP-I-containing mouth rinse during a 6-month course of therapy, despite resulting in significant iodine absorption (estimated as $6 \mathrm{mg}$ / rinse, though measurements of urinary iodine excretion suggested the lower value of 2-4 mg), showed no evidence of development of thyroid dysfunction [17]. This was despite an apparently quite high concentration in the mouth-rinse, i.e. $5 \%$ polyvinylpyrrolidone (PVP-I)-1.5\% $\mathrm{H}_{2} \mathrm{O}_{2}$ mixture (Perimed) or a 5\% PVP-I-water mixture [17].

\section{What are the Effects of Consumption of Excess lodine?}

lodide, needed for the biosynthesis of the thyroid hormones, thyroxine (T4, pro-hormone) and tri-iodothyronine (T3, active hormone) is taken up by the thyroid through the sodium-iodide symporter (NIS) [20]. One or two days of a high dose of iodide inhibits the synthesis of thyroid hormones, a process known as the Wolff-Chaikoff effect, which is an attempt to prevent the thyroid from synthesising excessive quantities of thyroid hormone [21]. This acute inhibition is mediated by the inactivation of the NIS at the plasma membrane and is dependent on the production and activity of reactive oxygen species (ROS) [22]. The inhibitory effect of excess iodide on NIS-mediated iodide transport can be triggered by hydrogen peroxide $\left(\mathrm{H}_{2} \mathrm{O}_{2}\right)$ treatment and reversed by ROS scavengers [22]. Indeed, excess iodide has been shown to increase $\mathrm{H}_{2} \mathrm{O}_{2}$ levels in slices of human thyroid glands [23]. Acute consumption of iodide of as little as one order of magnitude higher than the recommended dose for humans (i.e. 1,500 $\mu \mathrm{g} / \mathrm{d}$ vs. recommended intake of $150 \mu \mathrm{g} / \mathrm{d}$ [14] can cause the inactivation of the NIS at the plasma membrane [22]. The acute Wolff-Chaikoff effect lasts for some days, but thyroid-hormone synthesis can resume when the intrathyroidal inorganic iodine concentration falls as a result of downregulation of the NIS [21]. However, in some individuals, the escape from the inhibitory effect of large doses of iodide is not achieved and clinical or subclinical hypothyroidism ensues [21].

A lesser level of excess iodine intake than described above, or a rise in intake following iodine fortification of an iodine-deficient population, is known to increase the risk of thyroid autoimmunity, as attested by studies in many countries [24-35]. This is partly because highly iodinated thyroglobulin 


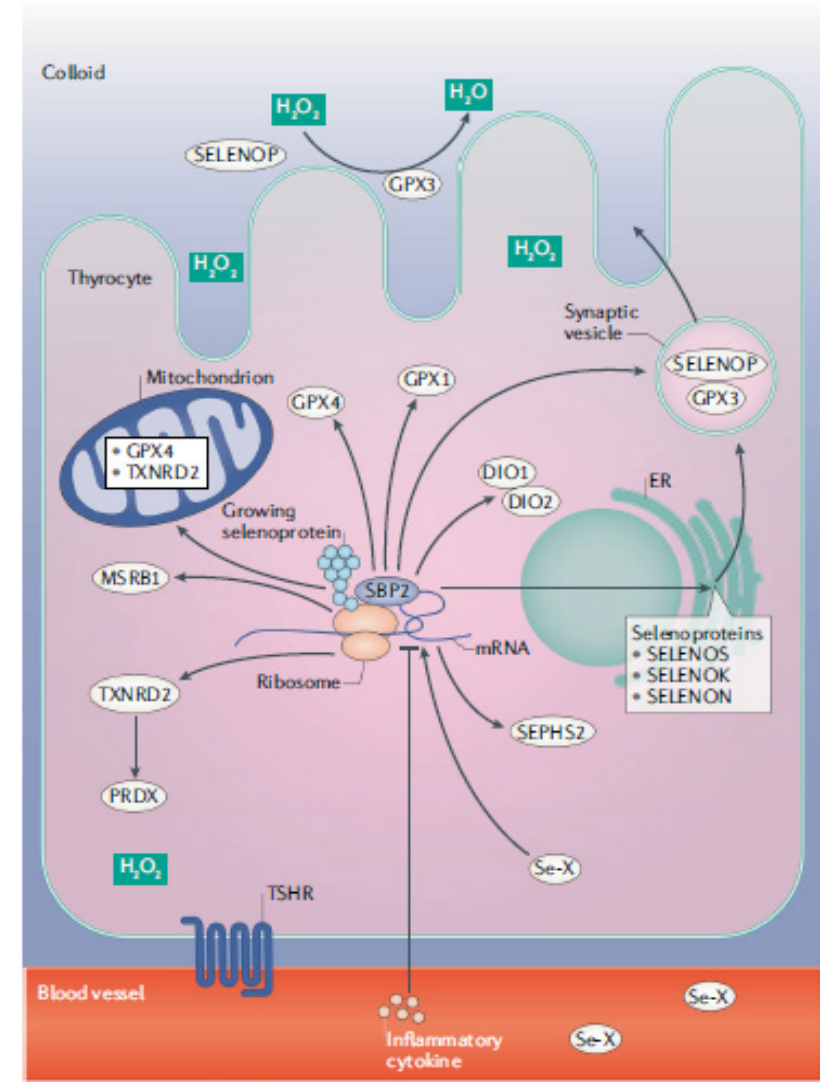

Figure 1: Selenoproteins are vital to the thyroid.

Selenoprotein $\mathrm{P}$ (SELENOP) and glutathione peroxidase 3 (GPX3) are actively secreted from the thyrocyte, whereas seven selenoproteins, including SELENOS and SELENOK, function in quality control pathways within the endoplasmic reticulum (ER). Type 1 iodothyronine deiodinase (DIO1), DIO2, GPX1, GPX4, MSRB1, SEPHS2 and TXNRD1 are intracellular selenoenzymes, whereas TXNRD2 and a GPX4 isozyme are localized in mitochondria. Selenocysteine insertion sequence (SECIS)-binding protein 2 (SECISBP2 or SBP2) is a rate-limiting factor controlling selenoprotein translation, which is negatively affected by inflammatory cytokines. Se-X denotes a seleno compound; MSRB1, methionine sulfoxide reductase B1; PRDX, peroxiredoxin; SEPHS2, selenophosphate synthetase 2; TSHR, thyroid stimulating hormone receptor; TXNRD, thioredoxin reductase. Adapted from Schomburg, Nature Reviews Endocrinology 2011 [41].

is strongly immunogenic and may trigger an immune reaction against the thyroid gland $[36,37]$. An additional factor may be that excess iodine intake increases the expression of the intercellular adhesion molecule-1 on the thyrocyte causing accelerated mononuclear cell infiltration and inflammation [37]. Other likely effects of high iodine intake in susceptible individuals are an increased production of thyroid-infiltrating T-helper 17 cells, inhibition of T-regulatory-cell development and an abnormal expression of TNF-related apoptosis-inducing ligand in thyrocytes, resulting in apoptosis and tissue destruction [38].

\section{Recommended Intake of lodine for Adults}

To reduce the risk of autoimmune thyroiditis, as far as possible, iodine intake should fall within the recommended levels, i.e. for adults, $150 \mu \mathrm{g} / \mathrm{d}$ [14]. The Tolerable Upper Intake Level (UL) of iodine for adults according to the European Food Safety Authority (EFSA) is $600 \mu \mathrm{g} / \mathrm{d}$ [15], though the US Institute of Medicine has set the Tolerable Upper Limit at the higher value of $1,100 \mu \mathrm{g} / \mathrm{d}$ [14]. Higher intake than that is not recommended and may cause thyroid dysfunction [14].

\section{Protective Effect of Selenium in Excessive lodine Intake}

Selenium (Se) is of vital importance to thyroid health and protection [39]. Of all tissues, the thyroid gland contains the highest Se concentration in the human body, largely independent of the Se content of other organs [20]. The thyroid contains a large number of selenoproteins (Figure 1) [40,41]; extracellular glutathione peroxidase (GPX3), additional GPX family members (GPX1, GPX4), and several other selenoproteins are expressed in thyrocytes, in particular the thioredoxin reductases, TXNRD1 and TXNRD2, the iodothyronine deiodinases, DIO1 and DIO2 (which convert T4 to T3), SELENOF, SELENOP, SELENOM and SELENOS, the last of which reduces the inflammatory response in the thyroid $[40,42,43]$. The incorporation of iodide into thyroid hormones is catalysed by the haemoprotein, thyroid peroxidase (TPO), which uses $\mathrm{H}_{2} \mathrm{O}_{2}$ as co-substrate [20]. TPO catalyses both the iodination of tyrosyl residues of thyroglobulin and the $\mathrm{H}_{2} \mathrm{O}_{2}$-dependent coupling of iodinated tyrosyl residues to generate the iodothyronines, T4 and T3 [20]. When iodine intake is greater than requirements, the NIS is inhibited by production of ROS such as $\mathrm{H}_{2} \mathrm{O}_{2}$ at the plasma membrane, as explained above [22]. $\mathrm{H}_{2} \mathrm{O}_{2}$ builds up in the colloid lumen, as it is not being utilised for thyroid-hormone synthesis and can cause thyroid damage [22]. The high expression of the selenoprotein, GPX3, in thyrocytes and its secretion into the closed and protected colloid lumen (Figure 1) can remove $\mathrm{H}_{2} \mathrm{O}_{2}$ there [20]. However, additional precautions are required to protect both the cell membrane and the intracellular compartments from any $\mathrm{H}_{2} \mathrm{O}_{2}$ diffusing into the thyrocytes [20]. Selenoprotein involved in these functions are the GPX1 and GPX4 isozymes and the selenium dependent TXNRD enzymes [20].

There is evidence from cell culture, animal and human studies that Se protects the thyroid from excessive iodine exposure. Leoni and colleagues examined the effects of high iodide doses in rat thyroids and in PCCl3 thyroid cells from 0-72 hours following iodide administration [44]. The increased production of ROS led to an increase in TXNRD mRNA levels and enzyme activity which reduced the oxidative stress. Inhibition of TXNRD at either gene expression or activity levels prevented NIS recovery [44]. Besides its effects on NIS, the antioxidant role of TXNRD after excess iodide administration seems to be crucial for re-establishment of thyroid homeostasis and the recovery of thyroid hormone biosynthesis [44].

In a situation of more-than-adequate iodine intake such as currently exists in China following the introduction of Universal Salt lodisation [24], higher serum Se [median (IQR) 103.6 $(79.7,135.9)$ vs. $57.4(39.4,82.1) \mu \mathrm{g} / \mathrm{L}]$ was shown to be associated with significantly lower odds [OR $(95 \% \mathrm{Cl})$ ] of hypothyroidism $0.75(0.63,0.90)$, subclinical hypothyroidism 0.68 
$(0 \cdot 58,0.93)$,enlarged thyroid $(0.75(0.59,0.97)$ and, most notably, of autoimmune thyroiditis $[0.47(0.35,0.65)]$ [45]. The most common form of autoimmune thyroiditis (Hashimoto's thyroiditis) is defined by the presence of antibodies to thyroid peroxidase (TPO), the thyroid enzyme that oxidises iodide to iodine for thyroid hormone synthesis [39]. Numerous studies, though not all, have shown a reduction in TPO-antibody titre on Se supplementation $[40,41]$.

\section{Independent Relevance of Se to Viral Diseases}

Apart from the fact that adequate Se intake or status appears to protect against excessive iodine intake (most particularly by removing excessive $\mathrm{H}_{2} \mathrm{O}_{2}$ that can build up in the thyroid in iodine excess [20], Se is an important anti-viral factor in its own right as explained below.

Significant clinical benefits of Se supplementation have been demonstrated in a number of viral infections, as reviewed previously $[46,47]$. These include most notably, cocksackie B3 and Keshan Disease, named after the area in northeast China where it was endemic [48]; when the population was supplemented with Se, the incidence of Keshan-disease fell dramatically $[49,50]$. Other examples are HIV-1, where a negative correlation between Se status and mortality has been established [50,51], in liver cancer linked to hepatitis B [52], and in patients with "epidemic haemorrhagic fever", that was successfully treated with oral sodium selenite, giving an overall $80 \%$ reduction in mortality $[46,53]$. From the above data it appears that Se intake or status is relevant to a number of evolutionarily distinct viruses, via potential immunomodulatory effects that are fully consistent with the many essential roles of Se in the immune system [49] and its ability (especially in deficiency) to influence viral mutation and evolution [48].

\section{Relevance of Se or Selenoproteins to SARS- CoV-2 Infection and COVID-19 Disease}

There is already some evidence for a link between SARSCoV-2 infection and selenoproteins; infection of cultured Vero E6 cells with SARS-CoV-2 significantly reduced the expression of a number of selenoproteins (GPX4, TXNRD3, and the endoplasmic reticulum selenoproteins, SELENOS, SELENOK, SELENOF, SELENOM) while increasing the expression of the inflammatory cytokine, IL-6 [54]. Concomitant down-regulation of SELENOF, SELENOM, SELENOK and SELENOS by SARS-CoV-2 is likely to result in increased concentration of misfolded proteins in the ER and catastrophic ER stress. A direct mechanistic link between the reduced expression of SELENOS and the production of inflammatory cytokines has already been well documented [43]; such a mechanism may be relevant to the marked elevation of IL- 6 concentration induced by SARS-CoV-2 [55].

Our group analysed COVID-19 cumulative data on the specific date of 18 February 2020 in Chinese cities and found a significant association between cure rate and population Se status in cities outside Hubei province (of which Wuhan is the capital); $R^{2}=0.72$, F-test $p<0.0001$ [56]. On inspection of the Hubei data, it was notable that the cure rate in Enshi city, renowned for its high Se intake, at $36.4 \%$, was much higher than that of other Hubei cities where the overall cure rate was $13.1 \%$; indeed, the Enshi Cure rate was significantly different from that in the rest of Hubei $(p<0.0001)$. Similar inspection of data from provinces excluding Hubei showed that Heilongjiang Province in north-east China, a notoriously low-Se region, had a much higher death rate $(2.4 \%)$ than that of other provinces $(0.5 \%) ; p<0.0001$. We were also able to show in our analysis of cure rate vs. Se status in Chinese cities, that the cure rate reached a maximum (60\%) at a status corresponding to an intake of $188 \mu \mathrm{g} / \mathrm{d}$ [56].

Reinforcing our observed association between Se status and outcome of COVID-19 disease is a German study that found a pronounced deficit in total serum Se and SELENOP concentrations in COVID-19 patients when compared to reference data from a large European cross-sectional study [57]. Se status was significantly higher in samples from surviving COVID patients than from non-survivors (Se, $53.3 \pm 16.2$ vs. $40.8 \pm 8.1 \mu \mathrm{g} / \mathrm{L}$; SELENOP, (3.3 \pm 1.3 vs. $2.1 \pm 0.9 \mathrm{mg} / \mathrm{L})$ [57]. Of course, being an observational study, causality cannot be inferred. Indeed, the low Se status associated with severity could reflect reduced expression of SELENOP by inflammatory cytokines under acute-phase conditions [57]. However, the exceptionally low level of serum Se reached will inevitably have adverse effects on the concentration of protective selenoproteins which, according to Moghaddam and colleagues [57], argues for the potential relevance of some supplemental Se support in severe COVID disease.

\section{Current Selenium Status in Different Countries}

Se status varies markedly across the world. Recommended levels of intake vary between authorities and are largely based on the intake believed to maximise the activity of plasma GPX (GPX3) (though it is now recognised that that intake is insufficient to optimise plasma SELENOP, the selenoprotein that transports Se from the liver to other tissues). The US Recommended Dietary Allowance (RDA) is $55 \mu \mathrm{g} / \mathrm{d}$ for adults [58] while UK recommendations (Reference Nutrient Intake, RNI) are $75 \mu \mathrm{g} / \mathrm{d}$ for adult men and $60 \mu \mathrm{g} / \mathrm{d}$ for adult women [59]. Much of Europe does not meet these recommended intake levels; for instance, the most recent UK National Diet and Nutrition Survey (2014 -2016) found that $47 \%$ of women and $25 \%$ of men did not even reach the Lower Reference Nutrient Intake (LRNI, enough for only $2.5 \%$ of the population) of $40 \mu \mathrm{g} / \mathrm{d}[59,60]$. (Figure 2) shows the Se intake in different countries and also the level of intake believed to be required to optimise plasma GPX3 activity $[58,59]$ and that required to optimise SELENOP concentration [61]. Inspection of the figure will allow individuals to have some idea of their likely Se intake or status. However, clearly this will vary markedly from one person to another depending on whether rich sources of Se are eaten (seafood, meat and poultry in Europe and additionally cereals and grains in N America) [50]. Brazil nuts are a rich but very variable source of Se [50].

\section{Proposed Addition of Oral Se Supplemen- tation to those Using PVP-I Prophylactically}

For the reasons explained above, i.e., i) protection of the thyroid from exposure to excess iodine and, ii) the potential efficacy of Se in counteracting viral diseases, including 


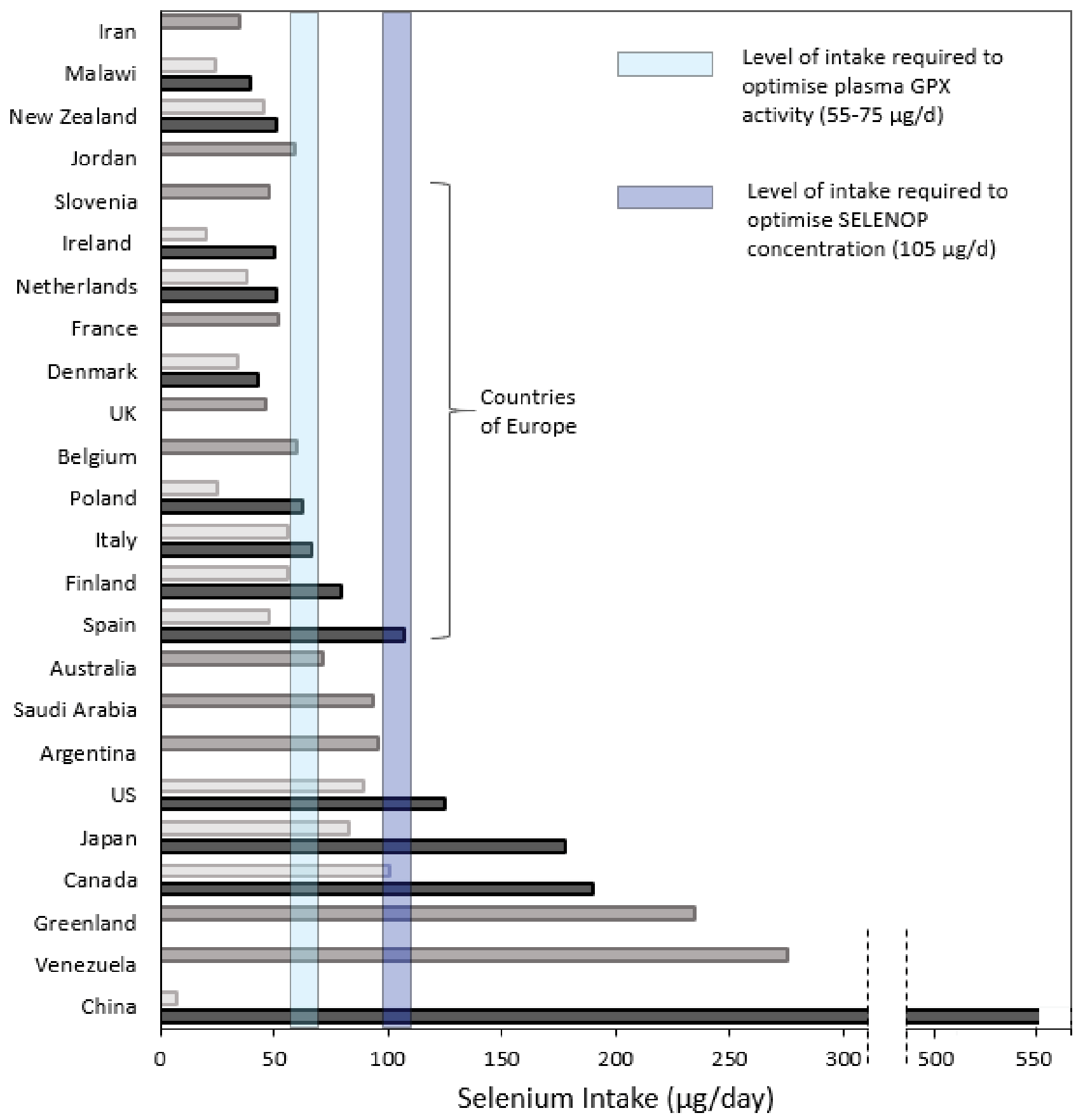

Figure 2: Selenium intake in different countries based on data published since 2000.

Where countries had more than one result, the highest value (dark grey) and the lowest value (pale grey) are shown. Where there was only one result, it is shown in mid-grey. Dietary intake data are only estimates and are recognized to be of variable quality and accuracy. (The figure for Venezuela is pre-2000 but is included as the value is notably high.) The turquoise band shows the level of intake believed to be required to optimise plasma GPX3 activity $[58,59]$ and the blue band shows that required to optimise SELENOP concentration [61]. GPX, plasma glutathione peroxidase; SELENOP, selenoprotein P (adapted from [40] with permission).

COVID-19, it is suggested that medical personnel, dental practitioners and patients frequently using nasal/throat sprays of PVP-I should be supplemented with Se at a dose that would achieve a total intake associated with a good cure rate, such as $100-200 \mu \mathrm{g} / \mathrm{d}$. The relevant supplementary dose must take the background intake into account as this will vary accord- ing to location (Figure 2). The proposed maximum dose (200 $\mu \mathrm{g} \mathrm{Se} / \mathrm{d}$ ) is not toxic, indeed it is consumed naturally in some parts of the world [40] (Figure 2). The Safe Upper Limit of Se intake has been defined as $400 \mu \mathrm{g} / \mathrm{d}$ [58]. In a randomised, controlled trial in Denmark, which has only a marginally sufficient Se status, a dose of $200 \mu \mathrm{g}$ Se/d was given for five years 
Citation: Rayman MP (2020) lodine and Selenium as Antiviral Agents: Potential Relevance to SARS-CoV-2 and Covid-19. Archives Oral Maxillofac Surg 3(1):69-76

to healthy elderly volunteers with no adverse effects compared to placebo [62].

A meta-analysis of 19 randomized controlled trials concluded that high-dose Se (upwards of $500 \mu \mathrm{g} /$ day), as sodium selenite, reduced the risk of all-cause mortality of critically-ill patients by $14 \%$ (RR 0.86; $95 \% \mathrm{Cl} 0.78,0.95 ; \mathrm{p}=0.002$ ) [63]. Further findings revealed that Se shortened the length of hospital stay by an average of 2.3 days. Supplementation with high doses of Se did not lead to an increased occurrence of side effects (RR 1.04; $95 \% \mathrm{Cl} 0.83,1.30 ; p=0.73$ ) [63].

There may be some question as to whether some patients or health-care workers should be assessed for their Se status before being given Se supplementation. This would be problematic insofar as it would delay supplementation by at least a week. Furthermore, with regard to COVID-19 patients, there is likely to be a systemic inflammatory response (as shown by increased C-reactive protein, IL-6 and other inflammatory cytokines [55], in which case, plasma/serum Se will fall owing to a reduction in SELENOP expression. In this situation, measurement of plasma Se or SELENOP will not reflect true (baseline) status. Erythrocyte Se, which is unaffected by the inflammatory response, can be measured to determine status [64] however, it is not a standard measurement in hospital trace-element labs. There is certainly no risk to supplementation up to $200 \mu \mathrm{g} \mathrm{Se} / \mathrm{d}$ for a limited period and indeed no evidence that such a level of supplementation is dangerous over a period of five years at the relatively low background Se status that is typical in Europe [62].

It would seem that prophylactic treatment with PVP-I spray $(0.5 \%)$ to the nose and throat followed by gargling is a strategy worth considering for anyone likely to be exposed to SARS-CoV-2 and particularly for those treating COVID-19 patients, given the safety of such treatment [65]. However, whether the PVP-I spray is effective against SARS-CoV-2 in vivo will have to wait for the outcome of the trials that have been registered and are hopefully underway [1].Combining with a daily supplement of 100-200 $\mu \mathrm{g}$ of Se (according to location), preferably in the form of sodium selenite which does not build up in the tissues [62] may be beneficial and is unlikely to cause harm in the short-to-medium term. To the author's knowledge, no randomised trial that will test Se against SARS-CoV-2 or COVID-19 has been initiated, though the author and colleagues have designed a trial protocol.

\section{Acknowledgement}

I should like to acknowledge the role of James D Combes [FDS RCS FRCS(OMFS), Lt Col RAMC, Clinical Director Oral and Maxillofacial Surgery, Royal Surrey County Hospital; Consultant Advisor (ARMY) in Oral and Maxillofacial Surgery in alerting me to the use of povidone-iodine as a virucidal agent with the potential to protect against SARS-CoV-2 infection in healthcare workers who work close to the nose and mouth.

\section{References}

1. Meister TL, Brüggemann.Y, Todt, et al. (2020) Virucidal efficacy of different oral rinses against SARS-CoV-2. The Journal of infectious diseases 222: 1289-1292.

2. Kirk-Bayley J SV, Challacombe SJ, Combes J (2020) The use of
Povidone lodine nasal spray and mouthwash during the current COVID-19 pandemic may reduce cross infection and protect healthcare workers. SSRN Pre-print Posted: 30 Mar 2020.

3. (2013) Encyclopedia of polymer science and technology, $3^{\text {rd }}$ edn, John Wiley \& Sons, 728.

4. Farrar D (2011) Advanced therapies wound repair. 1st Edn, Woodhead Publishing Series in Biomaterials: Woodhead Publishing.

5. Parhar HS, Tasche K, Brody RM, et al. (2020) Topical preparations to reduce SARS-CoV-2 aerosolization in head and neck mucosal surgery. Head Neck 42: 1268-1272.

6. Kariwa H, Fujii N, Takashima I (2006) Inactivation of SARS coronavirus by means of povidone-iodine, physical conditions and chemical reagents. Dermatology 212: 119-123.

7. Eggers $M$, Koburger-Janssen T, Eickmann M, et al. (2018) In vitro bactericidal and virucidal efficacy of povidone-iodine gargle/ mouthwash against respiratory and oral tract pathogens. Infect Dis Ther 7: 249-259.

8. Anderson DE, Sivalingam V, Kang AEZ, et al. (2020) Povidone-iodine demonstrates rapid in vitro virucidal activity against SARSCoV-2, The virus causing COVID-19 disease. Infect Dis Ther 9: 669-675.

9. Bidra AS, Pelletier JS, Westover JB, et al. (2020) Rapid in-vitro inactivation of severe acute respiratory syndrome coronavirus 2 (SARS-CoV-2) using povidone-iodine oral antiseptic rinse. J Prosthodont 29: 529-533.

10. Frank S, Capriotti J, Brown SM, et al. (2020) Povidone-iodine use in sinonasal and oral cavities: A review of safety in the COVID-19 era. Ear Nose Throat J 99: 586-593.

11. Khan MM, Parab SR, Paranjape M (2020) Repurposing $0.5 \%$ povidone iodine solution in otorhinolaryngology practice in Covid 19 pandemic. Am J Otolaryngol 41: 102618.

12. Challacombe SJ, Kirk-Bayley J, Sunkaraneni VS, et al. (2020) Povidone iodine. BDJ 228: 656-657.

13. Pullen G, Croser D (2020) Reducing transmission in a dental setting. British Dental Journal 228: 656.

14. Institute of Medicine (US) PoM (2001) Dietary reference intakes for vitamin A, vitamin $\mathrm{K}$, arsenic, boron, chromium, copper, iodine, iron, manganese, molybdenum, nickel, silicon, vanadium, and zinc. National Academies Press (US), Washington (DC).

15. Scientific Committee on Food, Scientific Panel on Dietetic Products NaA (2006) Tolerable upper intake levels for vitamins and minerals. EFSA

16. Verger P, Aurengo A, Geoffroy B, et al. (2001) lodine kinetics and effectiveness of stable iodine prophylaxis after intake of radioactive iodine: A Review. Thyroid 11: 353-360.

17. Ader AW, Paul TL, Reinhardt W, et al. (1988) Effect of mouth rinsing with two polyvinylpyrrolidone-iodine mixtures on iodine absorption and thyroid function. J Clin Endocrinol Metabol 66: 632-635.

18. Ferguson MM, Geddes DA, Wray D (1978) The effect of a povidone-iodine mouthwash upon thyroid function and plaque accumulation. Br Dent J 144: 14-16.

19. Nelson N, Palmes ED, Park CR, et al. (1947) The absorption, excretion and physiological effect of iodine in normal human subjects. J Clin Invest 26: 301-310. 
Citation: Rayman MP (2020) lodine and Selenium as Antiviral Agents: Potential Relevance to SARS-CoV-2 and Covid-19. Archives Oral Maxillofac Surg 3(1):69-76

20. Schomburg L, Kohrle J (2008) On the importance of selenium and iodine metabolism for thyroid hormone biosynthesis and human health. Mol Nutr Food Res 52: 1235-1246.

21. Markou K, Georgopoulos N, Kyriazopoulou V, et al. (2001) lodine-Induced hypothyroidism. Thyroid 11: 501-510.

22. Arriagada AA, Albornoz E, Opaz MC, et al. (2015) Excess iodide induces an acute inhibition of the sodium/iodide symporter in thyroid male rat cells by increasing reactive oxygen species. Endocrinology 156: 1540-1551.

23. Corvilain B, Collyn L, van Sande J, et al. (2000) Stimulation by iodide of $\left.\left.\mathrm{H}_{2}\right) \mathrm{O}_{2}\right)$ generation in thyroid slices from several species. Am J Physiol Endocrinol Metabol 278: E692-E699.

24. Teng W, Shan Z, Teng X, et al. (2006) Effect of iodine intake on thyroid diseases in China. N Engl J Med 354: 2783-2793.

25. Teng $X$, Shan Z, Chen Y, et al. (2011) More than adequate iodine intake may increase subclinical hypothyroidism and autoimmune thyroiditis: A cross-sectional study based on two Chinese communities with different iodine intake levels. Eur J Endocrinol 164: 943-950.

26. Peng NC, Shi LX, Zhang Q, et al. (2013) An epidemiological survey of the prevalence of thyroid diseases in mild iodine deficiency city after salt iodization. Zhonghua nei ke za zhi 52: 16-20.

27. Zhang JY, Li SM, Leng JL, et al. (2013) Changes of the spectrum on thyroid disease after the ten-year implementation of universal salt iodization in Guangxi Zhuang Autonomous Region. Zhonghua liu xing bing xue za zhi 34: 970-974.

28. Pedersen IB, Knudsen N, Carle A, et al. (2011) A cautious iodization programme bringing iodine intake to a low recommended level is associated with an increase in the prevalence of thyroid autoantibodies in the population. Clin Endocrinol 75: 120-126.

29. Bjergved L, Jorgensen $T$, Perrild $H$, et al. (2012) Predictors of change in serum TSH after iodine fortification: an 11-year follow-up to the DanThyr study. J Clin Endocrinol Metabol 97: 4022-4029.

30. Cerqueira C, Knudsen N, Ovesen L, et al. (2011) Doubling in the use of thyroid hormone replacement therapy in Denmark: Association to iodization of salt? Eur J Epidemiol 26: 629-635.

31. Camargo RY, Tomimori EK, Neves SC, et al. (2008) Thyroid and the environment: exposure to excessive nutritional iodine increases the prevalence of thyroid disorders in Sao Paulo, Brazil. EurJ Endocrinol 159: 293-299.

32. Zaletel K, Gaberscek S, Pirnat E (2011) Ten-year follow-up of thyroid epidemiology in Slovenia after increase in salt iodization. Croat Med J 52: 615-621.

33. Fernando RF, Chandrasinghe PC, Pathmeswaran AA (2012) The prevalence of autoimmune thyroiditis after universal salt iodisation in Sri Lanka. Ceylon Med J 57: 116-119.

34. Aghini LF, Fiore E, Tonacchera M, et al. (2013) The effect of voluntary iodine prophylaxis in a small rural community: The Pescopagano survey 15 years later. J Clin Endocrinol Metabol 98: 1031-1039.

35. Luo Y, Kawashima A, Ishido $Y$, et al. (2014) lodine excess as an environmental risk factor for autoimmune thyroid disease. Int J Mol Sci 15: 12895-12912.

36. Zimmermann MB, Boelaert $\mathrm{K}$ (2015) lodine deficiency and thyroid disorders. lancet Diabetes Endocrinol 3: 286-295.

37. Burek CL, Talor MV (2009) Environmental triggers of autoim- mune thyroiditis. J Autoimmun 33: 183-189.

38. Duntas LH (2015) The Role of lodine and Selenium in Autoimmune Thyroiditis. Horm Metab Res 47: 721-726.

39. Rayman MP (2019) Multiple nutritional factors and thyroid disease, with particular reference to autoimmune thyroid disease. Proc Nutr Soc 78: 34-44.

40. Winther KH, Rayman MP, Bonnema SJ, et al. (2020) Selenium in thyroid disorders - essential knowledge for clinicians. Nat Rev Endocrinol 16: 165-176.

41. Schomburg $L$ (2011) Selenium, selenoproteins and the thyroid gland: Interactions in health and disease. Nat Rev Endocrinol 8: 160-171.

42. Santos LR, Duraes C, Mendes A, et al. (2014) A polymorphism in the promoter region of the selenoprotein S gene (SEPS1) contributes to Hashimoto's thyroiditis susceptibility. J Clin Endocrinol Metab 99: E719-E723.

43. Curran JE, Jowett JB, Elliott KS, et al. (2005) Genetic variation in selenoprotein $\mathrm{S}$ influences inflammatory response. Nat genet 37: 1234-1241.

44. Leoni SG, Kimura ET, Santisteban P, et al. (2011) Regulation of thyroid oxidative state by thioredoxin reductase has a crucial role in thyroid responses to iodide excess. Mol endocrinol 25: 1924-1935.

45. Wu Q, Rayman P, Lv H, et al. (2015) Low population selenium status is associated with increased prevalence of thyroid disease. J Clin Endocrinol Metabol 100: 4037-4047.

46. Taylor EW, Ruzicka JA, Premadasa L, et al. (2016) Cellular selenoprotein $\mathrm{mRNA}$ tethering via antisense interactions with ebola and HIV-1 mRNAs may impact host selenium biochemistry. Curr Top Med Chem 16: 1530-1535.

47. Steinbrenner H, Al-Quraishy S, Dkhil, et al. (2015) Dietary selenium in adjuvant therapy of viral and bacterial infections. Adv Nutr 6: 73-82.

48. Beck MA, Handy J, Levander OA et al. (2004) Host nutritional status: the neglected virulence factor. Trends Microbiol 12: 417423.

49. Hoffmann PR, Berry MJ (2008) The influence of selenium on immune responses. Mol Nutr Food Res 52: 1273-1280.

50. Rayman MP (2012) Selenium and human health. Lancet 379: 1256-1268.

51. Baum MK, Shor-Posner G, Lai, et al. (1997) High risk of HIV-related mortality is associated with selenium deficiency. Journal of acquired immune deficiency syndromes and human retrovirology: Official publication of the International Retrovirology Association 15: 370-374.

52. Yu SY, Zhu YJ, Li WG, et al. (1997) Protective role of selenium against hepatitis $B$ virus and primary liver cancer in Qidong. Biol Trace Elem Res 56: 117-124.

53. Hou JC (1997) Inhibitory effect of selenite and other antioxidants on complement-mediated tissue injury in patients with epidemic hemorrhagic fever. Biol Trace Elem Res 56:125-130.

54. Wang Y, Huang J, Sun Y, et al. (2020) SARS-CoV-2 suppresses mRNA expression of selenoproteins associated with ferroptosis, ER stress and DNA synthesis. bioRxiv preprint 2020.

55. Zhang J SR, Taylor EW, Rayman MP et al. (2020) Selenium and selenoproteins in viral infection with potential relevance to COVID-19. Redox Biology 37: 101715 
56. Zhang J TE, Bennett K, Saad R, et al. (2020) Association between regional selenium status and reported outcome of COVID-19 cases in China. Am J Clin Nutr 1: 1297-1299

57. Moghaddam A, Heller RA, Sun Q (2020) Selenium Deficiency Is Associated with Mortality Risk from COVID-19 Nutrients 16: 12.

58. Institute of Medicine (US), Panel on Dietary Antioxidants and Related Compounds (2000) Dietary Reference Intakes for Vitamin C, Vitamin E, Selenium, and Carotenoids. National Academies Press, Washington DC, USA.

59. Department of Health (1991) Dietary reference values of the committee on medical aspects of food policy (COMA), in dietary reference values for food, energy and nutrients for the United Kingdom. H.M Stationery Office, London.

60. https://www.gov.uk/government/statistics/ndns-results-fromyears-7-and-8-combined
61. Hurst R, Armah CN, Dainty, et al. (2010) Establishing optimal selenium status: Results of a randomized, double-blind, placebo-controlled trial. Am J Clin Nutr 91: 923-931.

62. Rayman MP, Winther KH, Pastor-Barriuso, et al. (2018) Effect of long-term selenium supplementation on mortality: Results from a multiple-dose, randomised controlled trial. Free Radic Biol Med 1: 46-54.

63. Zhao Y, Yang M, Mao Z, et al. (2019) The clinical outcomes of selenium supplementation on critically ill patients: A meta-analysis of randomized controlled trials. Medicine 98: e15473.

64. Stefanowicz FA, Talwar D, O'Reilly, et al. (2013) Erythrocyte selenium concentration as a marker of selenium status. Clin Nutr 32: 837-842.

65. Vergara-Buenaventura A, Castro-Ruiz C (2020) Use of mouthwashes against COVID-19 in dentistry. Br J Oral Maxillofac Surg 58: 924-927. 